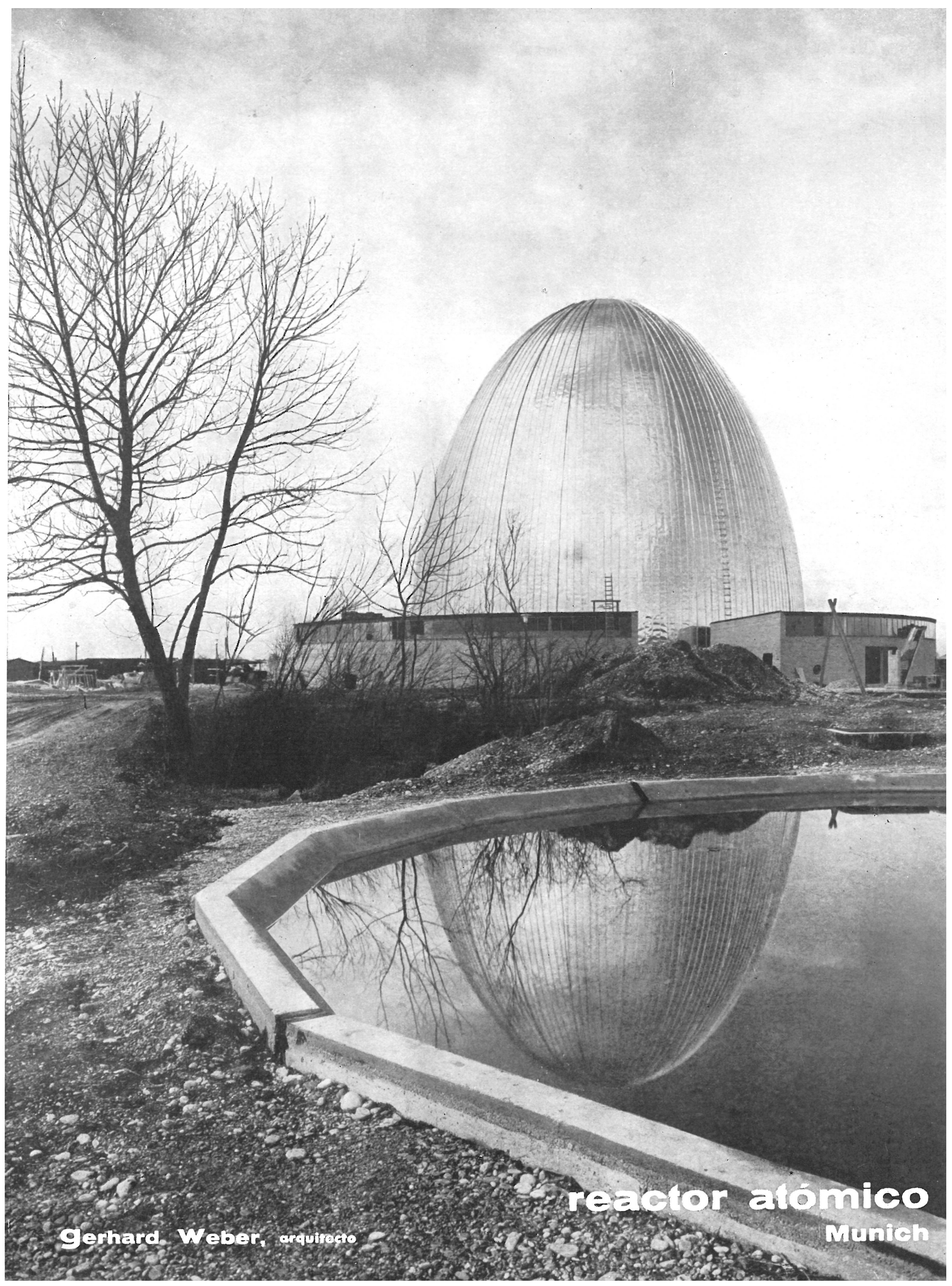




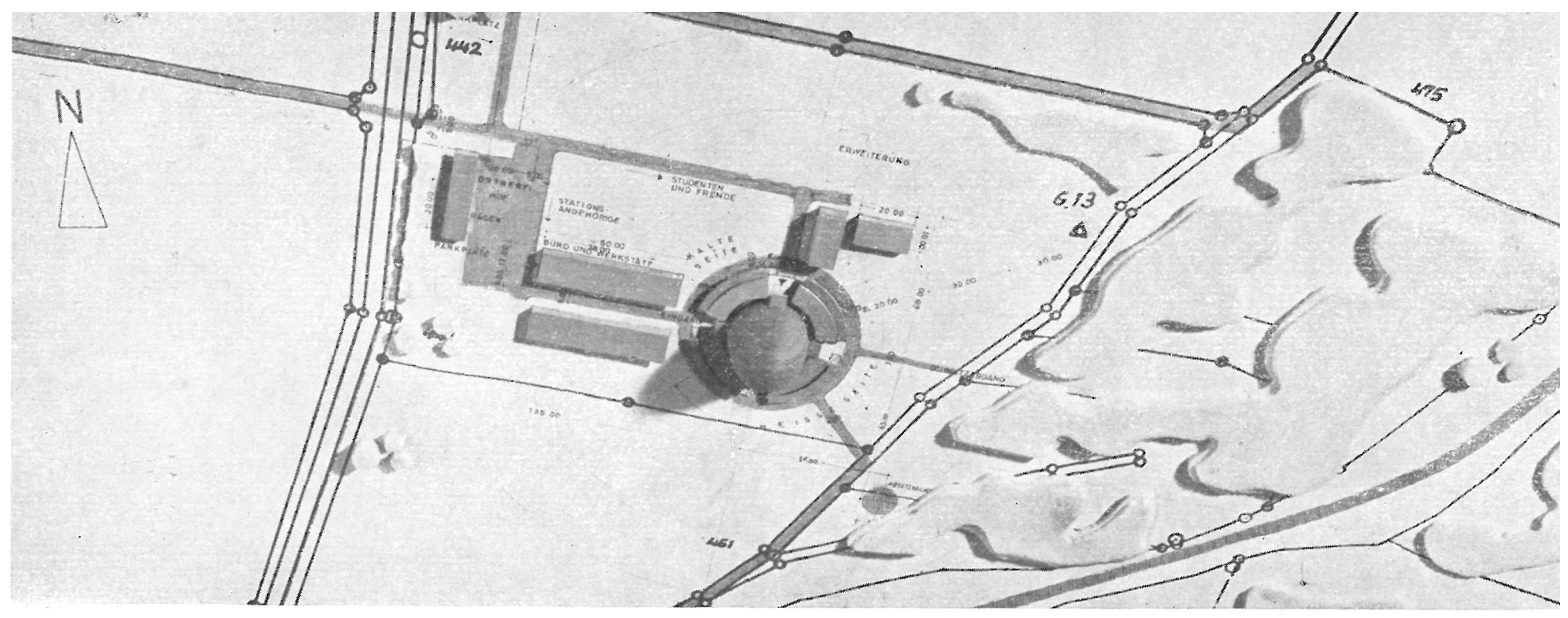

$591-1$

Una vez más el espíritu alemán ha quedado definido por su gran capacidad para la iniciación de empresas duras y difíciles con la construcción de esta estación atómica, creada para corresponder a las necesidades del Instituto de Física en la Escuela Superior Técnica de $\mathrm{Mu}$ nich.

La inexperiencia de los técnicos en este tipo de construcciones llegó al extremo de que los dirigentes de dicha Escuela Superior dudaron sobre si los planos para el proyecto de esta estación se deberían comprar en América, junto con el reactor propiamente dicho, o si los arquitectos alemanes deberían llevar a cabo un proyecto propio, decidiéndose al final en favor de un proyecto alemán, cuyo realizador debía de tener la cualidad de conocer a fondo la construcción de edificios industriales para poder proyectar una instalación capaz, a pesar de la falta de datos sobre las dimensiones.

Las fuentes de documentación con que contó el arquitecto fueron las publicaciones de ejemplos realizados en América; proyectos alemanes aún en embrión, faltos por consiguiente de valor, y un dibujo detallado del reactor con los datos suministrados por la firma americana proveedora.

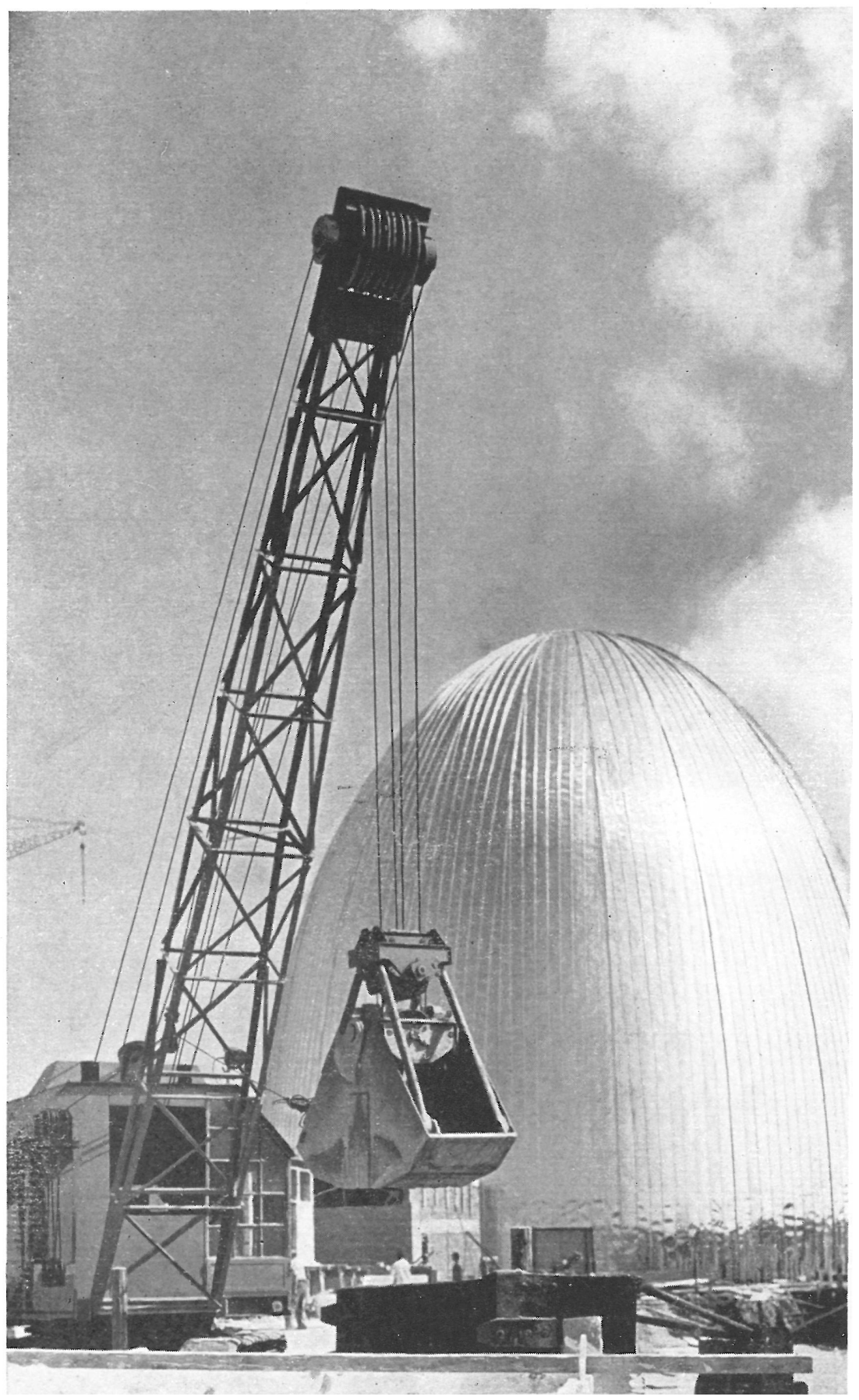




\section{secciones transversales}
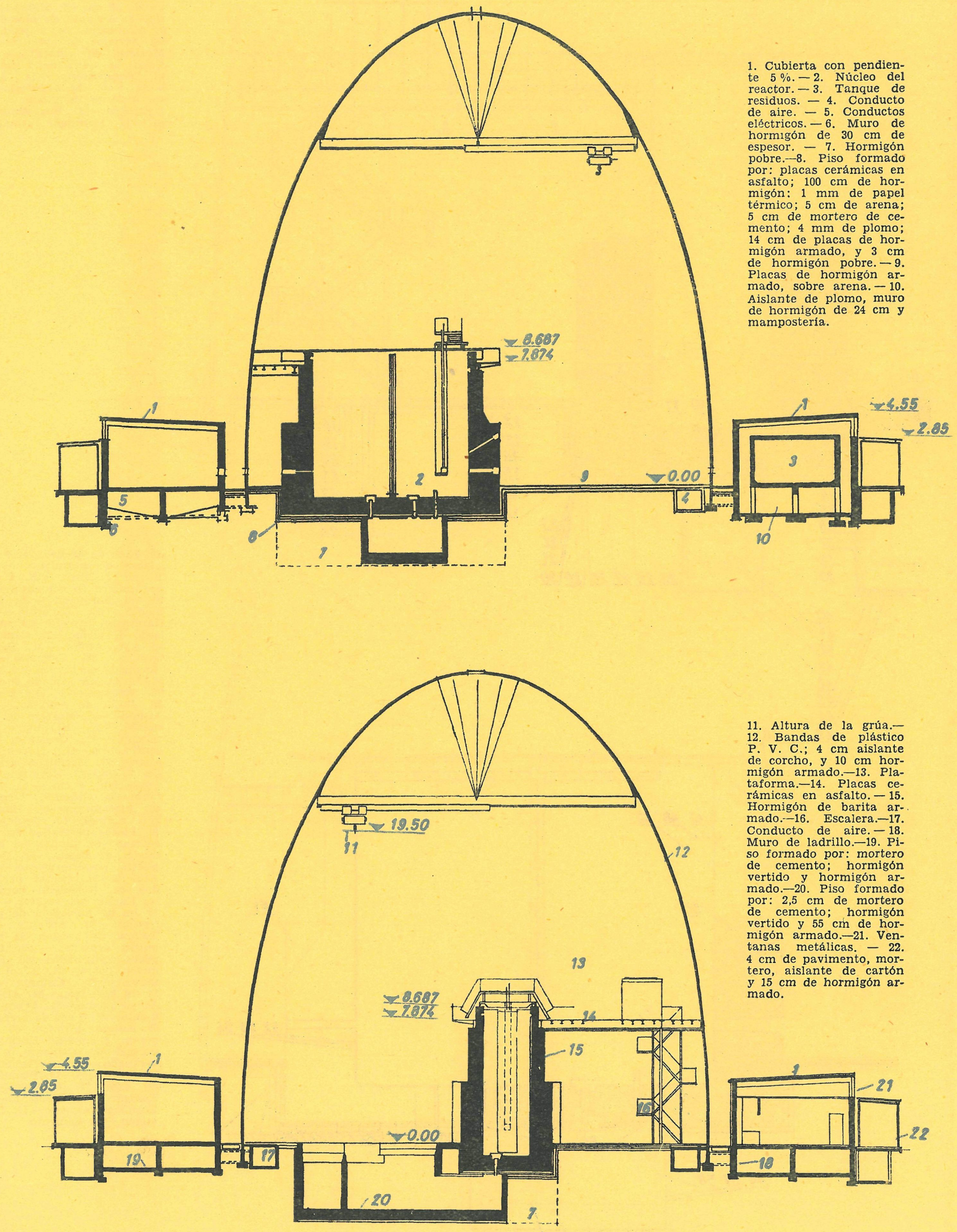


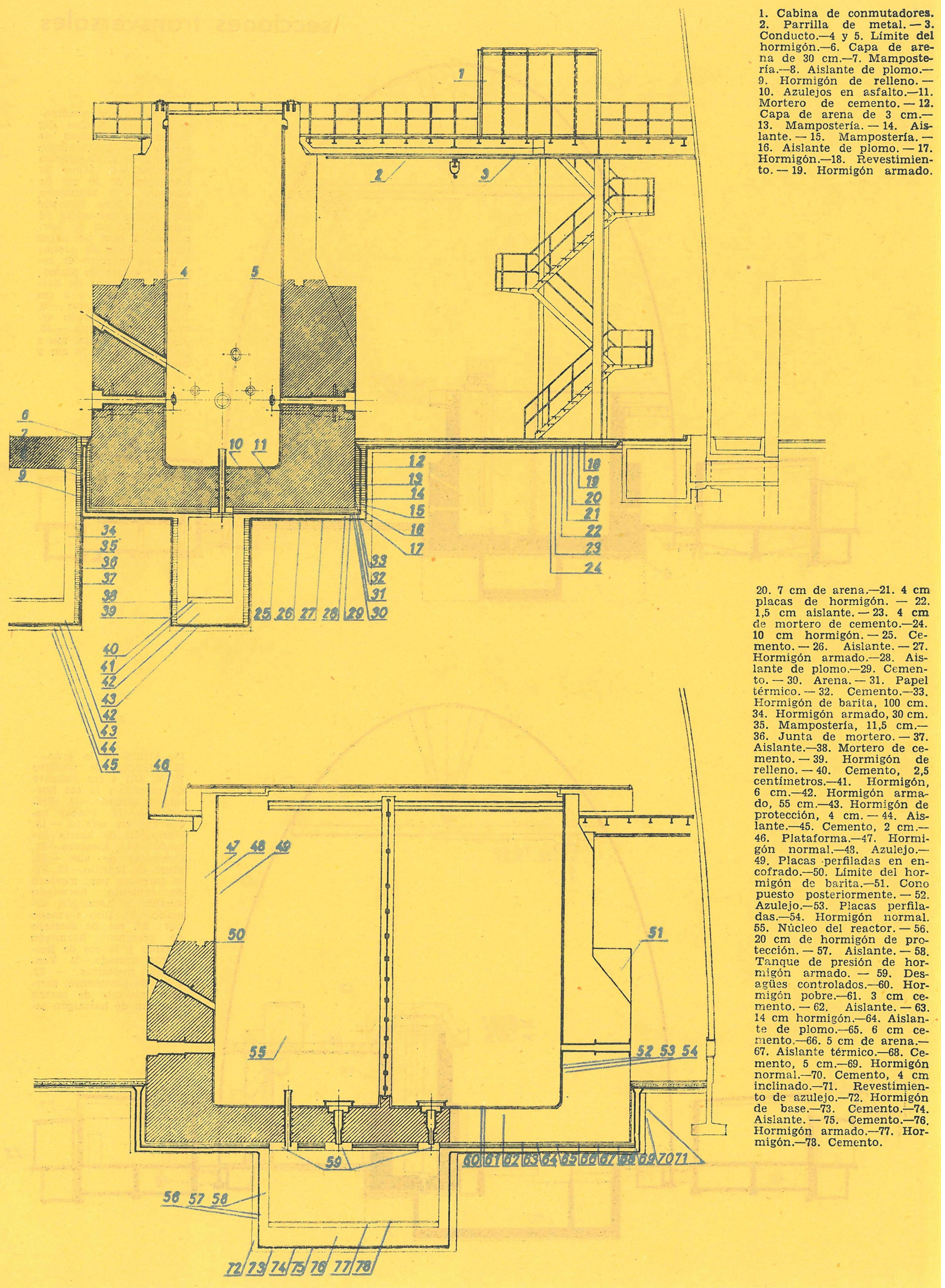



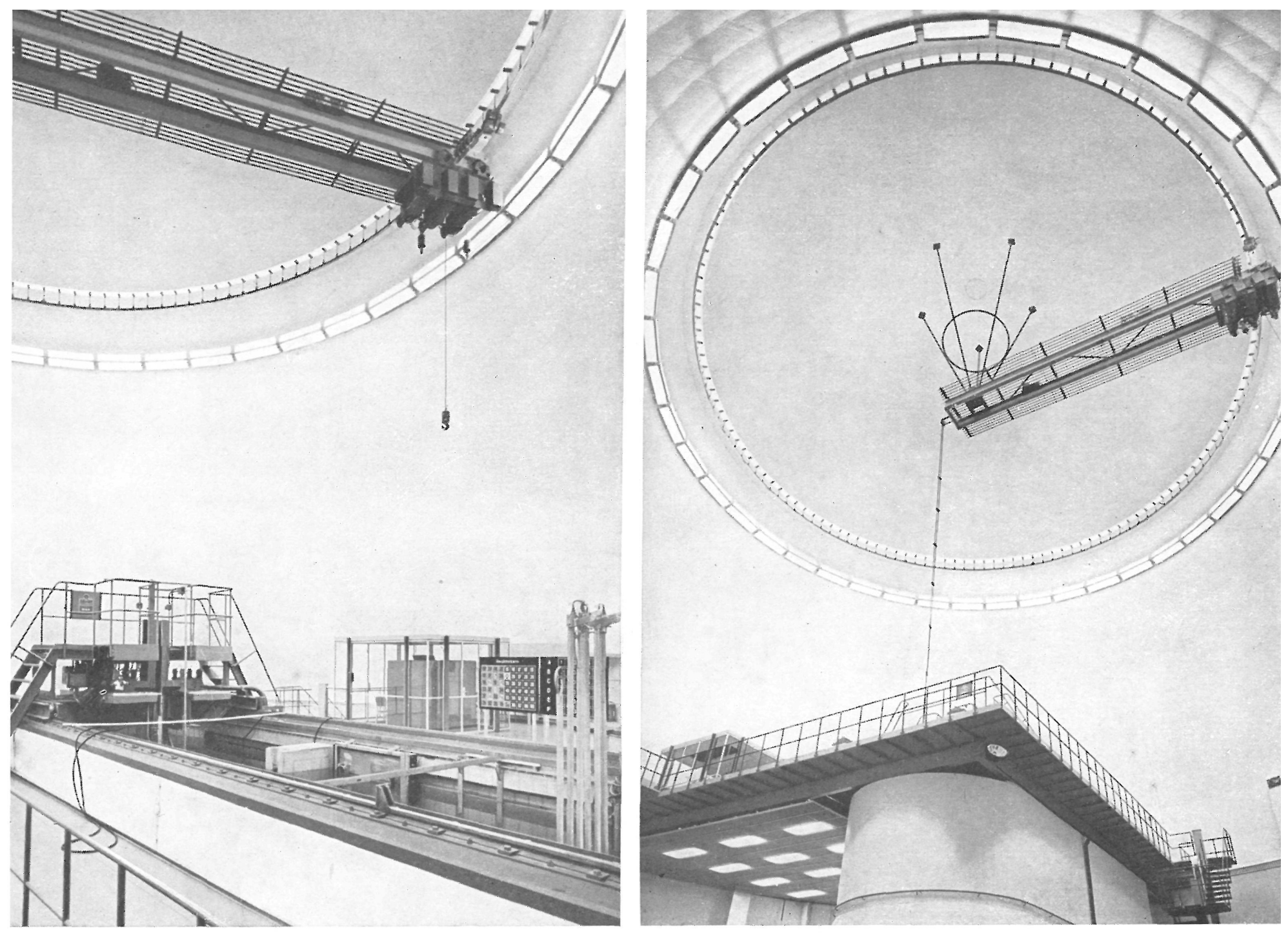

A esta falta de fuentes inspiradoras y de consulta, debemos añadir la dificultad para la elección de un lugar adecuado que reuniera las condiciones exigidas de emplazamiento, facilidad de acceso y agua subterrânea.

$\mathrm{Y}$ todos estos obstáculos han sido allanados y superados por el arquitecto Gerhard Weber, el cual ha Iogrado conjugar armónicamente dos factores, tan dispares cuando no se tratan bien, como el funcionalismo y la estética.

El conjunto consta de un edificio principal de planta circular y cinco naves rectangulares que albergan los servicios auxiliares: talleres, oficinas, almacén, etc.

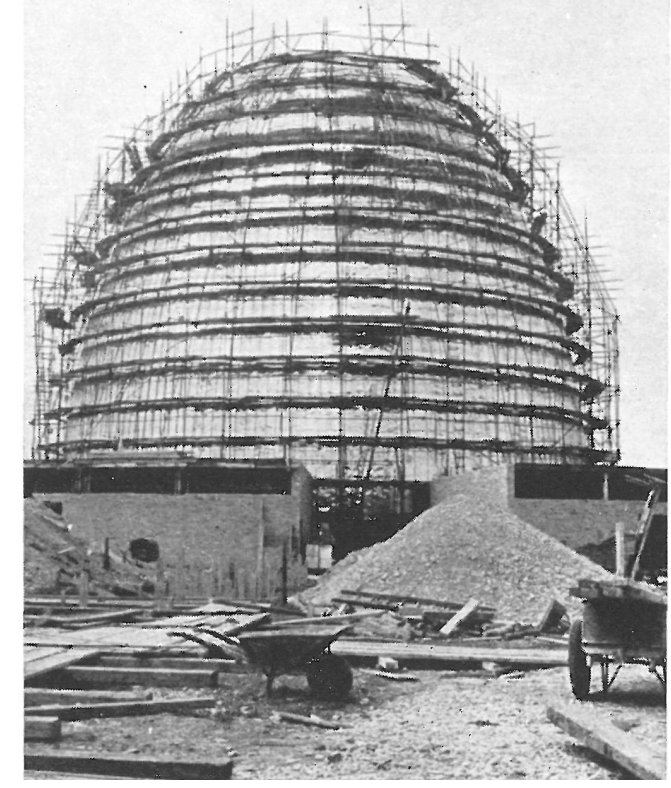



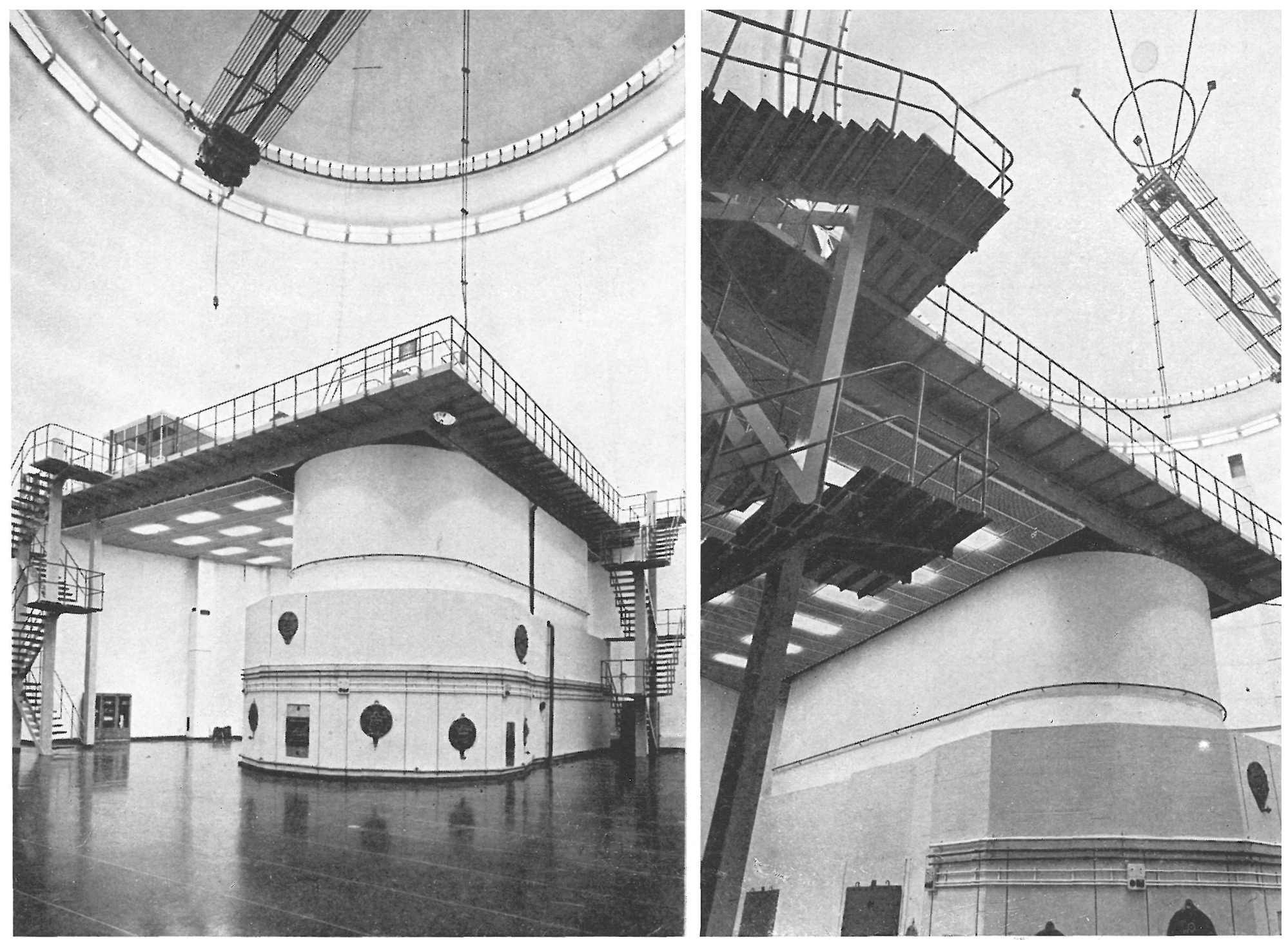

Interiores del reactor.

El edificio principal contiene un hall; una gran superficie para ensayos con puente-grúa, y una plataforma a la altura de la fuente que sirve para trabajos preparativos y para el servicio del reactor. Por motivos de seguridad, este edificio principal está separado, aislado y sin aberturas al exterior. Su forma elipsoidal, de $30 \mathrm{~m}$ de diámetro y altura, fué sugerida por el arquitecto y confirmada por ingenieros después de las oportunas comprobaciones.

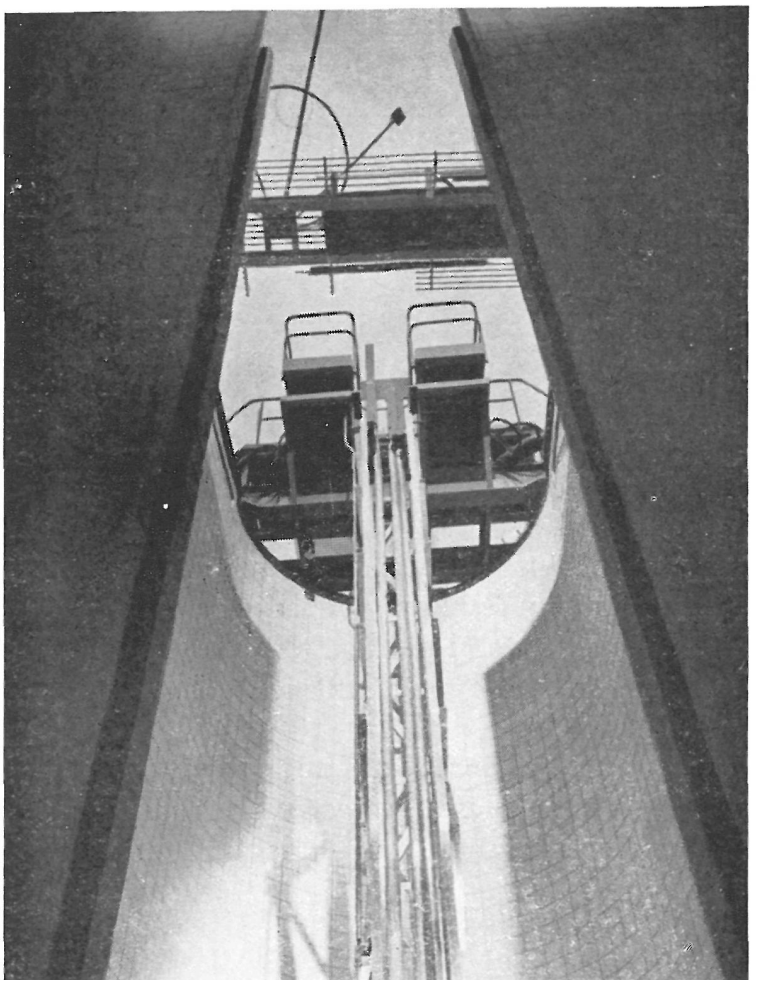

